\section{GRAPHIC DETAIL}

\section{The real value of a scientist's wage}

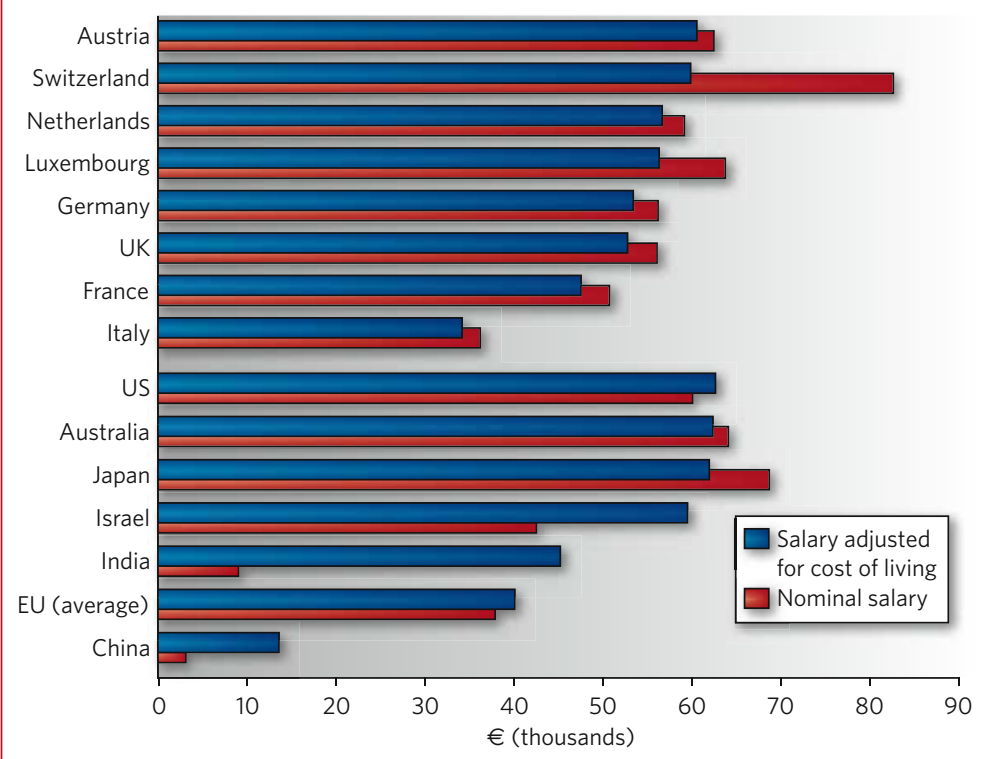

If money is the measure of all things, Austria may be the most attractive country in Europe for a working scientist. And India is close to Europe's leading science nations, even though the average gross salary for researchers there is a meagre $€ 9,200$ (US $\$ 13,600)$. That's according to data comparing scientists' salaries, after taking into account the cost of living.

The European Commission report includes data on the 2006 salaries of thousands of scientists working in the public and private sectors across 38 countries. The information was gathered from an online survey as well as from national databases.

The cost-of-living figures show that only Austria, Switzerland, the Netherlands, Luxembourg and Israel offer salaries similar to those in the United States, Australia and Japan.

Unweighted, Switzerland $(€ 82,700)$ has the highest gross salary worldwide. Bulgaria $(€ 3,600)$ and China $(€ 3,200)$ have the lowest salaried scientists of the countries in the study.

There are striking differences within the member countries of the European Union (EU). On average, EU researchers can expect $€ 22,500$ less than their colleagues in the United States, Japan and Australia - after the cost of living is factored in. "This huge disparity certainly contributes to our top people seeing better opportunities elsewhere in the world," warns EU research commissioner Janez Potočnik, who announced the results on 13 November. Quirin Schiermeier 